\title{
Eritrocitose associada a tumor venéreo transmissível em cão: relato de caso
}

\author{
[Erythrocytosis in a dog with transmissible venereal tumor: case report]

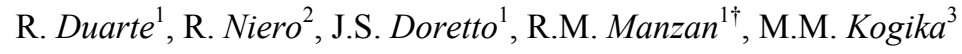 \\ ${ }^{1}$ Curso de Medicina Veterinária - CREUPI-SP - São Paulo, SP \\ ${ }^{2}$ Médica Veterinária Autônoma \\ ${ }^{3}$ Faculdade de Medicina Veterinária e Zootecnia - USP - São Paulo, SP \\ $\dagger$ In memoriam
}

\begin{abstract}
RESUMO
Descreve-se um caso de eritrocitose absoluta (hematócrito: 74\%, hemoglobina: $24,2 \mathrm{~g} / \mathrm{dl}$ ) em um cão com tumor venéreo transmissível cutâneo. A concentração de hemoglobina e o hematócrito retornaram ao valor normal após o tratamento com vincristina. A remissão da eritrocitose após o tratamento é sugestiva de uma associação entre o tumor e a alteração hematológica.
\end{abstract}

Palavras-chave: cão, tumor venéreo transmissível, eritrocitose, eritropoietina

\begin{abstract}
This report describes a case of absolute erythrocytosis (hematocrit: $74 \%$, hemoglobin: $24.2 \mathrm{~g} / \mathrm{dl}$ ) in a dog with transmissible cutaneous venereal tumor. Hemoglobin and hematocrit returned to normal range after the treatment with vincristine. The remission of the erythrocytosis after treatment suggests a relationship between the neoplastic lesions and the hematological abnormality.
\end{abstract}

Keywords: dog, transmissible venereal tumor, erythrocytosis, erythropoietin

\section{INTRODUÇÃO}

O tumor venéreo transmissível canino (TVT) é uma neoplasia contagiosa que acomete principalmente a mucosa da genitália externa dos cães. O acometimento cutâneo e intranasal são as mais comuns depois da forma venérea (Brandão et al., 2002). Embora já tenham sido descritos casos de metástases, geralmente as complicações do TVT estão relacionadas ao crescimento do tumor no tecido em que este está implantado. Síndromes paraneoplásicas, i.e, manifestações clínicas decorrentes dos efeitos indiretos e, normalmente, remotos, produzidas por metabólitos de células tumorais e outros produtos, não foram descritas em cães com TVT adquirido naturalmente. A eritrocitose, um aumento na massa total de eritrócitos do sangue, é uma síndrome paraneoplásica que já foi descrita em associação com diversos tipos de tumores em seres humanos e cães. Relata-se a ocorrência de eritrocitose em um caso de TVT cutâneo em uma cadela.

\section{CASUÍSTICA}

Uma cadela, SRD, com sete anos de idade e com peso de $5,5 \mathrm{~kg}$ foi atendida no Hospital Veterinário do CREUPI devido ao aparecimento de formações cutâneas, perda de peso e intolerância a exercícios. $\mathrm{O}$ animal tinha histórico de TVT vaginal, tratado de forma irregular.

Ao exame físico, mostrava-se um animal alerta, sem características de desidratação. As mucosas estavam congestas e foi detectado sopro (grau

Recebido em 10 de fevereiro de 2005

Aceito em 12 de setembro de 2006

E-mail: creupi2002@yahoo.com.br 
IV/VI) em todos focos cardíacos. Também foram observadas cinco formações de consistência macia, não aderidas, de $1 \mathrm{a} 3 \mathrm{~cm}$ de diâmetro em região cervical, torácica-lateral esquerda e direita, lombar e anal, duas delas ulceradas e hemorrágicas (Fig. 1). Não havia lesões genitais.

Pelos exames complementares, constatou-se eritrocitose (hematócrito: 74\%, hemácias: $8 \times 10^{6} / \mathrm{mm}^{3}$, hemoglobina: 24,2g/dl), sem alterações nas demais linhagens de células sangüíneas, e proteínas totais séricas normais $(7,1 \mathrm{~g} / \mathrm{dl})$. Por meio da análise citológica do aspirado das lesões cutâneas e anal, concluiu-se que todas eram decorrentes de TVT (Fig. 2).

Seguiram-se, então, três flebotomias, com intervalos semanais, nas quais foram retirados, respectivamente, 60, 20 e 40ml de sangue. Após cada flebotomia foi realizada reposição volêmica com solução de Ringer com lactato, na quantidade igual ao dobro do volume de sangue retirado. O animal também foi medicado com maleato de enalapril $(0,5 \mathrm{mg} / \mathrm{kg}$ a cada $12 \mathrm{~h})$.

Um mês após a consulta inicial, o hematócrito ainda era alto $(67 \%)$, sendo, então, realizados gasometria (saturação arterial de $\mathrm{O}_{2}$ : 94,1\%), dosagem da concentração sérica de eritropoetina $\left(\right.$ Epo) ${ }^{1}$, que era igual a $36,3 \mathrm{mU} / \mathrm{ml}$ (valores de referência: 5,2 a 40,0 $\mathrm{mU} / \mathrm{ml}$ [Notomi, 2003]) e mielograma. Pela análise citológica da medula óssea observou-se hiperplasia moderada de série eritróide, com discreta diseritropoiese em estágio final de maturação, sem alterações na morfologia ou escala maturativa da série mielóide (relação mielóide:eritróide 0,82; normal: de 1,0 a 2,5) e discreta hiperplasia de série megacariocítica, sem alterações morfológicas.

Foi realizado exame ultra-sonográfico dos rins, nos quais não foi observada qualquer alteração, bem como nos demais órgãos abdominais. À ecocardiografia com doppler, observou-se espessamento das valvas mitral, tricúspide e aórtica, sugestivo de endocardiose. Também foi observado fluxo retrógrado de sangue através dessas valvas, denotando insuficiência valvar de moderada a marcante. A fração de ejeção era normal $(0,8)$.

\footnotetext{
${ }^{1}$ EPO-Trac ${ }^{125}$ I RIA kit, DiaSorin Inc., Stillwater.
}

Após esses exames, foi realizada nova flebotomia $(60 \mathrm{ml})$, seguida de reposição volêmica, e a primeira aplicação semanal de sulfato de vincristina, na dose de $0,75 \mathrm{mg} / \mathrm{m}^{2}$, para tratamento do TVT. Ao final da quinta semana de tratamento com vincristina, quando já havia remissão completa das lesões cutâneas, o hematócrito do animal era 41\%. Flebotomias adicionais não foram realizadas.

Quase um mês após a última aplicação de vincristina, o estado clínico do animal era considerado ótimo, com ganho de peso $(0,5 \mathrm{~kg})$, e o hematócrito havia se mantido estável (44\%). Nessa ocasião, a concentração de Epo era de $21,7 \mathrm{mU} / \mathrm{ml}$. Na última avaliação do animal, aproximadamente quatro meses após a última, os valores hematimétricos eram normais (hematócrito: $43 \%$, hemácias: $6,7 \times 10^{6} / \mathrm{mm}^{3}$, hemoglobina: $13,7 \mathrm{~g} / \mathrm{dl}$ ). O curso do tratamento está sumarizado na Fig. 3.

\section{DISCUSSÃO}

A eritrocitose é o aumento da massa total de eritrócitos do sangue e pode ser classificada em: relativa, absoluta (primária e secundária [apropriada e inapropriada]). O diagnóstico definitivo do tipo de eritrocitose envolvido é essencial para a conduta terapêutica e baseia-se na exclusão das formas mais simples da doença (Couto et al., 1989). Deve-se descartar a eritrocitose relativa (hemoconcentração) e isso, em geral, pode ser conseguido pelo histórico, exame físico e exames complementares como, por exemplo, a mensuração de proteínas totais. $\mathrm{O}$ cão do presente relato não tinha características de desidratação nem histórico de condições predisponentes, como vômito ou diarréia e as proteínas plasmáticas totais eram normais.

O método considerado padrão para distinção entre eritrocitose relativa e absoluta, a mensuração da massa de eritrócitos, é pouco viável na prática, pois necessita de técnica de diluição radioisotópica, que consiste na infusão de hemácias radiomarcadas, seguida de flebotomias seriadas para determinação da sua distribuição, além de necessitar que o animal seja isolado por um período longo para prevenir a exposição dos proprietários à radiação (Couto et al., 1989; Stuart e Viera, 2004). 


\section{Duarte et al.}

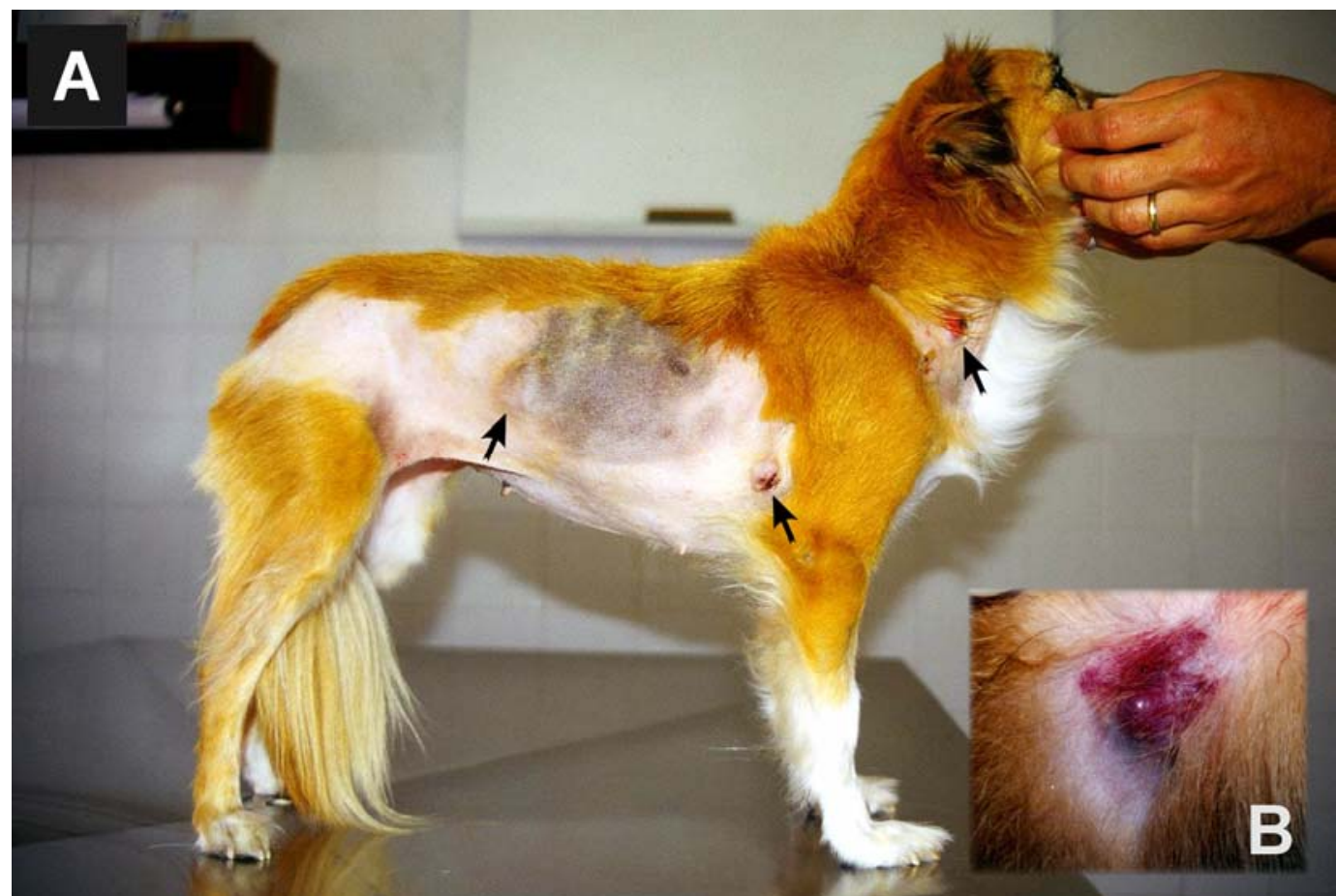

Figura 1. A - Lesões nodulares, de consistência firme e aderidas, em região abdominal, torácica e cervical lateral (setas). A extensa área sem pêlos é decorrente da seqüência de exames realizados. B - No detalhe, lesão nodular, purpúrea, medindo aproximadamente $2 \mathrm{~cm}$ de diâmetro, localizada na região cervical lateral esquerda.

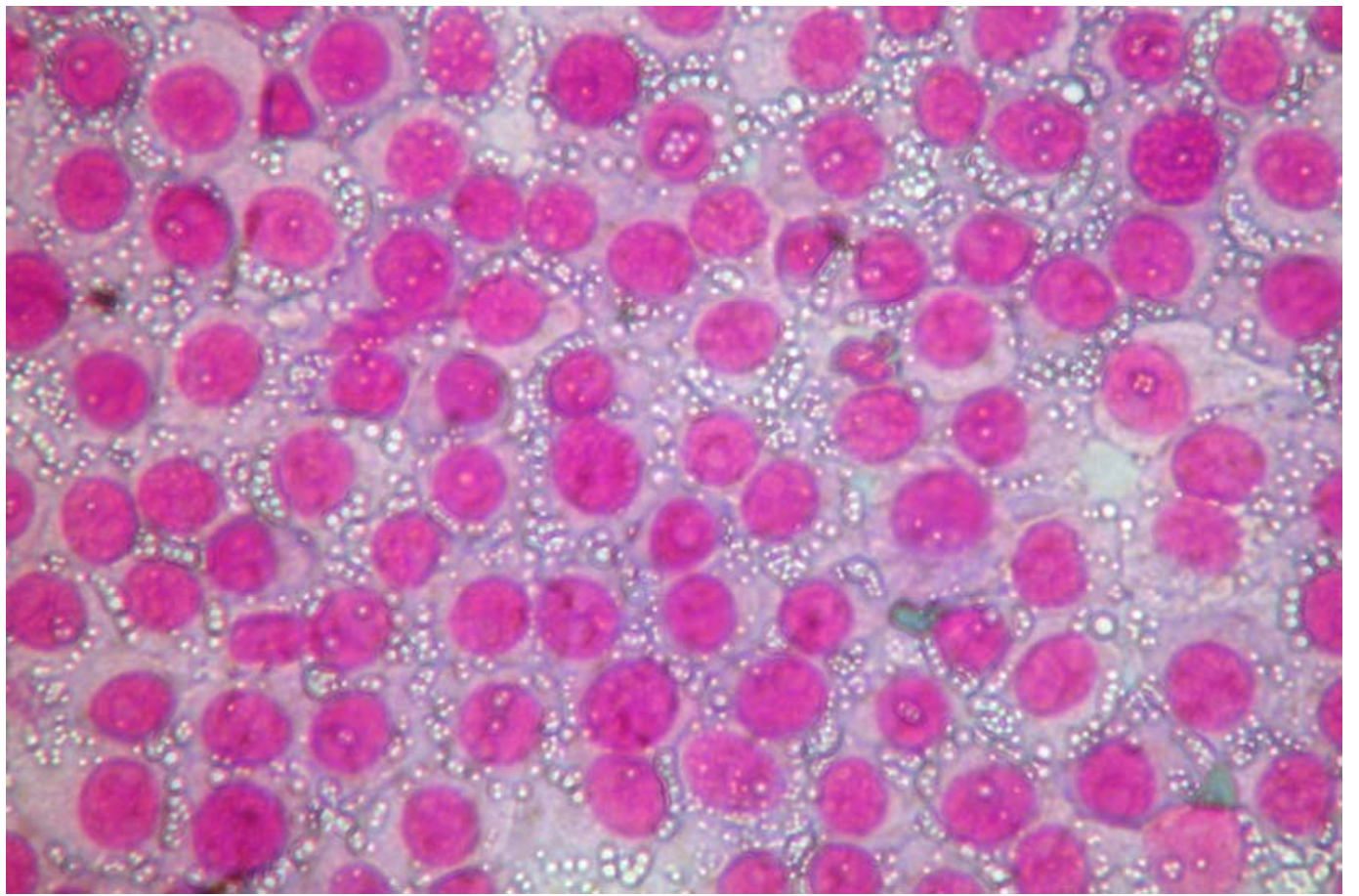

Figura 2. Fotomicrografia de preparado citológico obtido por aspirado com agulha fina de uma das lesões da cadela. Observar a grande quantidade de células redondas, com cromatina grosseira, nucléolos evidentes e grânulos citoplasmáticos. (Coloração: Rosenfeld, aumento 400x). 


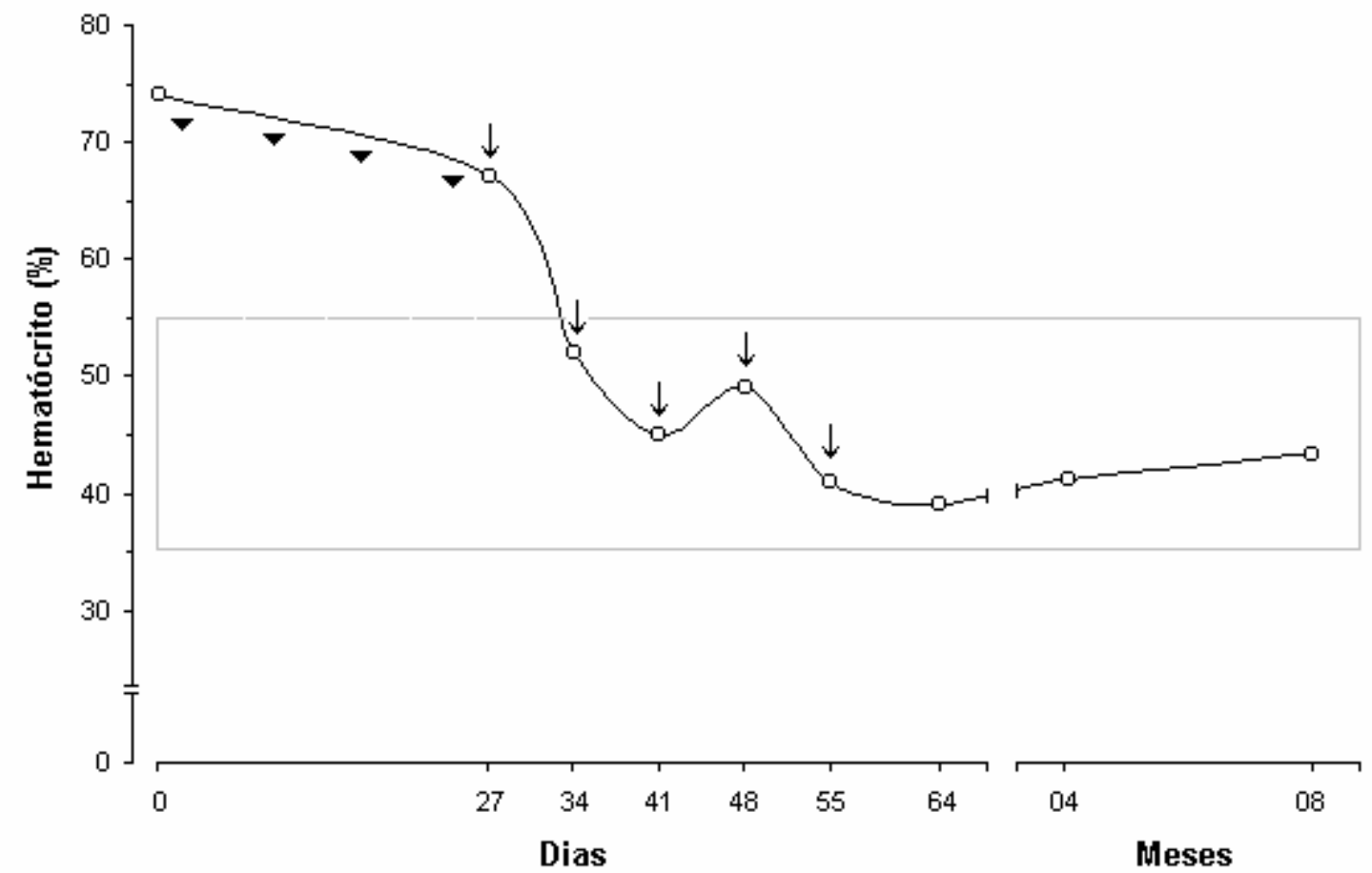

Figura 3. Variação do hematócrito de cadela durante e após o tratamento. As "gotas" (৬) indicam os dias da realização das flebotomias e as setas $(\downarrow)$ indicam os dias de administração do sulfato de vincristina. O retângulo cinza representa o intervalo de referência do hematócrito.

A eritrocitose absoluta secundária apropriada é decorrente da produção de Epo pelos rins em resposta à hipoxemia e ocorre em anomalias vasculares cardio-respiratórias, como estenose pulmonar e persistência do ducto arterioso com desvio da direita para esquerda. No presente relato, o paciente não tinha hipoxemia, nem evidências ecográficas de alterações que causassem diminuição da oxigenação renal.

Como desconhece-se a condição cardiovascular do animal, anterior à sua admissão no Hospital, as alterações ecocardiográficas não puderam ser relacionadas à eritrocitose. Num estudo, baseado em um modelo murino de eritrocitose crônica, os camundongos desenvolveram dilatação e hipertrofia biventricular marcantes. Esses animais também tinham intolerância ao exercício quando comparados a camundongos do grupo controle (Wagner et al., 2001). Exceto pela intolerância ao exercício, as alterações supracitadas não foram observadas no cão deste relato.
A eritrocitose absoluta secundária inapropriada geralmente é decorrente de neoplasias de origem renal. No caso de tumores renais, a obstrução do fluxo sangüíneo normal do órgão pode levar a um aumento da produção de Epo devido a hipóxia. A eritrocitose pode ocorrer também em casos de neoplasias extra-renais (eritrocitose paraneoplásica) e já foi descrita em associação com diversos tipos de tumores em seres humanos, como hepatomas, hemangiossarcomas cerebelares e tumores adrenocorticais. Algumas neoplasias não renais também têm sido associadas a eritrocitose em cães, como carcinoma nasal, fibrossarcoma nasal, schwanoma, neoplasias hepáticas e adenocarcinomas (Couto et al., 1989; Yamauchi et al., 2004). O mecanismo mais aceito para se explicar a eritropoiese paraneoplásica é o da produção de substâncias que estimulam a eritropoiese (eg, andrógenos, corticosteróides) ou produção ectópica de Epo, ou substância Eposímile, pelo tecido tumoral. 
Existe um estudo em que foi observado o aumento do hematócrito e das concentrações séricas de Epo em cães com TVT induzido experimentalmente (Cohen, 1985). A eritrocitose foi observada em animais com grande volume tumoral $\left(>300 \mathrm{~cm}^{3}\right)$. Nesse estudo, o autor concluiu que a eritrocitose era decorrente da produção de Epo pelas células tumorais, com base na extração do hormônio do tecido neoplásico. No presente caso, o volume tumoral total calculado correspondia a aproximadamente $56 \mathrm{~cm}^{3}$ e a concentração sérica de Epo estava próxima ao limite superior dos valores de referência, o que é inapropriado devido à condição de eritrocitose. A concentração sérica de Epo também estava reduzida ao final do tratamento, com a remissão da eritrocitose e do TVT. Essa associação temporal é sugestiva da produção ectópica de Epo, mas seriam necessários estudos biomoleculares e de imunoistoquímica para se comprovar a produção de Epo pelo tecido neoplásico (Yamauchi et al., 2004).

Esses achados devem ser interpretados com cuidado. Existe a hipótese que a hipóxia renal e subseqüente aumento da produção de Epo podem ocorrer devido à hiperviscosidade, associada a aumentos extremos do hematócrito (Mackin, 1994). Além disso, a acurácia da mensuração das concentrações desse hormônio em cães é limitada quando do uso de ensaios que utilizam anticorpos monoclonais contra Epo humana (como o utilizado nesse caso), pois a Epo canina é somente $85 \%$ homóloga à humana (Cook e Lothrop, 1994).

A avaliação da medula óssea foi realizada para excluir a hipótese de uma síndrome mieloproliferativa. Os achados do mielograma não foram compatíveis com proliferação neoplásica de elementos eritroblásticos (e não havia eritroblastos atípicos no sangue periférico). Os achados até então eram compatíveis com eritrocitose absoluta primária, classicamente chamada de policitemia vera (PV). A PV associada a concentrações normais de Epo já foi relatada em cães (Cook e Lothrop, 1994). Entretanto, nesse estudo, o diagnóstico de PV foi baseado na exclusão de outras causas de eritrocitose. Para o diagnóstico definitivo de PV é necessária a demonstração do crescimento de colônias eritróides em meios isentos de Epo
(Stuart e Viera, 2004), outro método não disponível na prática clínica.

Optou-se por manejar a eritrocitose por meio de flebotomias semanais, até que novos exames pudessem ser realizados. $\mathrm{O}$ volume de sangue removido foi menor do que o previamente recomendado $(20 \mathrm{ml} / \mathrm{kg})$, pois a causa da eritrocitose era desconhecida e havia a preocupação de não se causarem alterações bruscas do volume sangüíneo. Em um relato sobre cães com eritrocitose decorrente de persistência de ducto arterioso, um animal apresentou fraqueza dos membros posteriores após a flebotomia (Moore e Stepien, 2001). Neste relato, as flebotomias foram ineficazes em reduzir o hematócrito a uma porcentagem considerada adequada, mas nenhuma complicação foi observada.

Como a etiologia da eritrocitose ainda permanecia incerta, optou-se por iniciar $\mathrm{o}$ tratamento do TVT com vincristina. Também foi planejada a realização de flebotomias semanais até se atingir hematócrito menor que $45 \%$, valor alvo em seres humanos (Stuart e Viera, 2004). Porém, no decorrer da quimioterapia, o hematócrito decaiu e permaneceu estável, precluindo a realização de novas flebotomias.

Nesse caso, a remissão da eritrocitose após o tratamento do TVT é sugestiva de uma associação entre o tumor e a alteração hematológica, pois é improvável que o tratamento com vincristina resultasse na remissão total e prolongada de uma síndrome mielodisplásica, como a PV. Entretanto, a hipótese de produção ectópica de Epo não foi comprovada. Recomenda-se o escrutínio da eritrocitose em cães com TVT, principalmente naqueles com grande volume tumoral e maior investigação da produção ectópica da Epo nesses animais.

\section{AGRADECIMENTOS}

Às médicas veterinárias S.I. Miyashiro e L.O.D. Barbusci pela colaboração. 


\section{REFERÊNCIAS BIBLIOGRÁFICAS}

BRANDÃO, C.V.S.; BORGES, A.G.; RANZANI, J.J.T. et al. Tumor venéreo transmissível: estudo retrospectivo de 127 casos (1998-2000). Rev. Educ. Contin. CRMV-SP, v.5, p.25-31, 2002.

COHEN, D. The canine transmissible venereal tumor: a unique result of tumor progression. $A d v$. Cancer Res., v.43, p.75-112, 1985.

COOK, S.M.; LOTHROP Jr., C.D. Serum erythropoietin concentrations measured by radioimmunoassay in normal, polycythemic, and anemic dogs and cats. J. Vet. Intern. Med., v.8, p.18-25, 1994.

COUTO, C.G.; BOUDRIEAU R.J.; ZANJANI, E.D. Tumor-associated erythrocytosis in a dog with nasal fibrosarcoma. J. Vet. Intern. Med., v.3, p.183-185, 1989.

HOLDEN, A.R. Polycythaemia vera in a dog. Vet. Rec., v.120, p.473-475, 1987.

MACKIN, A. Serum erythropoietin assays. $J$. Vet. Intern. Med., v.8, p.314-315, 1994.
MOORE, K.W.; STEPIEN, R.L. Hydroxyurea for treatment of polycythemia secondary to rightto-left shunting patent ductus arteriosus in 4 dogs. J. Vet. Intern. Med., v.15, p.418-421, 2001.

NOTOMI, M.K. Anemia na insuficiência renal crônica de cães cocker spaniel inglês. 2003. 99f. Tese (Doutorado) - Faculdade de Medicina Veterinária e Zootecnia, Universidade de São Paulo, São Paulo, SP.

STUART, B.J.; VIERA, A.J. Polycythemia vera. Am. Fam. Physician, v.69, p.2139-2144, 2004.

WAGNER, K.F.; KATSCHINSKI, D.M.; HASEGAWA, J. et al. Chronic inborn erythrocytosis leads to cardiac dysfunction and premature death in mice overexpressing erythropoietin. Blood, v.97, p.536-542, 2001.

YAMAUCHI, A.; OHTA, T.; OKADA, T. et al. Secondary erythrocytosis associated with schwannoma in a dog. J. Vet. Med. Sci. v.66, p.1605-1608, 2004. 